\title{
VENTX induces expansion of primitive erythroid cells and contributes to the development of acute myeloid leukemia in mice
}

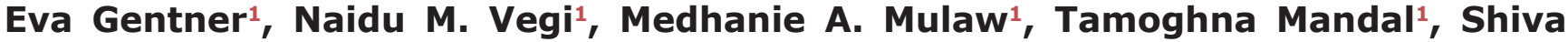 \\ Bamezai $^{1}$, Rainer Claus ${ }^{2}$, Alpaslan Tasdogan ${ }^{3}$, Leticia Quintanilla-Martinez ${ }^{4}$,

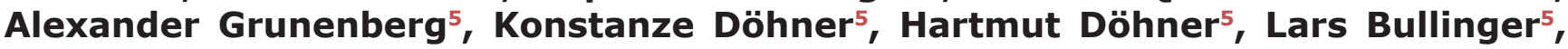 \\ Torsten Haferlach ${ }^{6}$, Christian Buske ${ }^{1}$, Vijay P.S. Rawat ${ }^{1, *}$, Michaela Feuring-Buske ${ }^{5, *}$ \\ ${ }^{1}$ Institute of Experimental Cancer Research, CCC and University Hospital of UIm, 89081 Ulm, Germany \\ ${ }^{2}$ Department of Internal Medicine I, University Hospital Freiburg, 79106 Freiburg, Germany \\ ${ }^{3}$ Institute of Immunology, Ulm University, 89081 UIm, Germany \\ ${ }^{4}$ Institute of Pathology, University of Tübingen, 72076 Tübingen, Germany \\ ${ }^{5}$ Department of Internal Medicine III, University Hospital Ulm, 89081 Ulm, Germany \\ ${ }^{6}$ MLL Munich Leukemia Laboratory, 81377 Munich, Germany \\ *These authors have contributed equally to this work \\ Correspondence to: Michaela Feuring-Buske, email: michaela.feuring-buske@uni-ulm.de \\ Keywords: acute erythroleukemia, VENTX, AML1-ETO, homeobox gene, embryonic transcription factor \\ Received: August 12,2016 Accepted: November 09, $2016 \quad$ Published: November 24, 2016
}

\section{ABSTRACT}

Homeobox genes are key regulators in normal and malignant hematopoiesis. The human Vent-like homeobox gene VENTX, a putative homolog of the Xenopus laevis Xvent-2 gene, was shown to be highly expressed in normal myeloid cells and in patients with acute myeloid leukemia. We now demonstrate that constitutive expression of VENTX suppresses expression of genes responsible for terminal erythroid differentiation in normal $\mathrm{CD}_{34}{ }^{+}$stem and progenitor cells. Transplantation of bone marrow progenitor cells retrovirally engineered to express VENTX caused massive expansion of primitive erythroid cells and partly acute erythroleukemia in transplanted mice. The leukemogenic potential of VENTX was confirmed in the AML1ETO transplantation model, as in contrast to AML1-ETO alone co-expression of AML1ETO and VENTX induced acute myeloid leukemia, partly expressing erythroid markers, in all transplanted mice. VENTX was highly expressed in patients with primary human erythroleukemias and knockdown of VENTX in the erythroleukemic HEL cell line significantly blocked cell growth. In summary, these data indicate that VENTX is able to perturb erythroid differentiation and to contribute to myeloid leukemogenesis when co-expressed with appropriate AML oncogenes and point to its potential significance as a novel therapeutic target in AML.

\section{INTRODUCTION}

It has been shown that early developmental genes play a major role in adult hematopoiesis including orchestrating self-renewal and differentiation of hematopoietic stem and progenitor cells. This is exemplified by the family of homeobox genes, known to be key regulators in embryogenesis, but also during normal postnatal hematopoiesis [1]. Furthermore, it was shown that the role of homeobox genes extends beyond normal hematopoiesis, being critically involved in leukemogenesis. This role is well established for clustered HOX genes such as HOXA9, but also for nonclustered homeobox genes such as MEIS1, which is one of the most potent co-factors for HOX driven leukemias, or the Parahox gene CDX2 [2-4]. We recently described 
the human Vent-like homeobox gene VENTX, a putative homolog of the Xenopus laevis Xvent-2 gene, as a novel regulatory hematopoietic gene, which in contrast to leukemogenic HOX genes such as HOXA9 and HOXA10 is highly expressed in normal myeloid cells, but not in early $\mathrm{CD} 34^{+}$stem and progenitor cells. Constitutive expression of VENTX in normal $\mathrm{CD}^{+} 4^{+}$human progenitor cells impaired lymphoid engraftment and fostered generation of myeloid cells, but failed to induce leukemia in vivo. This was in contrast to our observation that VENTX was highly expressed in human AML, in particular in patients with the translocation $\mathrm{t}(8 ; 21)$ which is associated with the most frequent fusion gene AML1ETO (AE) [5]. We now provide evidence that VENTX suppresses expression of erythroid master regulators, expands primitive erythroid cells and contributes to leukemogenesis in transplanted mice.

\section{RESULTS}

\section{VENTX impairs expression of genes involved in erythroid differentiation and is highly expressed in patients with acute erythroid leukemia and polycythemia vera}

Based on our previous findings that overexpression of VENTX is able to perturb normal hematopoietic differentiation, we first aimed at characterizing changes in the molecular profile induced by VENTX overexpression. For this VENTX was retrovirally expressed in normal human $\mathrm{CD}^{+} 4^{+}$cord blood (CB) cells for $48 \mathrm{~h}$ before performing RNA-sequencing (RNA-Seq) $(n=3) .278$ genes were differentially expressed between VENTX and the empty vector control (Supplementary Table S1, Figure 1A). Pathway analyses showed changes in the expression of genes belonging to the categories JAK-STAT signaling pathway, Hematopoietic cell lineage, Cytokine-cytokine receptor interaction and Hemoglobin's Chaperone (Supplementary Figure S1A-S1C, Supplementary Table S2). Strikingly, overexpression of VENTX significantly downregulated genes involved in erythropoiesis, among them several genes known as master regulators of erythropoiesis: thus, genes such as GATA1 (2.7-fold, $\mathrm{p}<0.0001)$, GATA2 (2.3fold, $\mathrm{p}<0.0001$ ), LDB1 (1.7-fold, $\mathrm{p}=0.001)$, KLF1 (5.0fold, $\mathrm{p}<0.0001)$, GFI1B (2.5-fold, $\mathrm{p}<0.0001), \mathrm{LMO} 2$ (1.7-fold, $\mathrm{p}<0.001)$ and TAL1 $(2.3$-fold, $\mathrm{p}<0.0001)$ were downregulated in $\mathrm{CD} 34^{+} \mathrm{CB}$ cells constitutively expressing VENTX. In parallel genes involved in heme and hemoglobin synthesis were significantly downregulated such as HBA1 (4.1-fold, $\mathrm{p}=0.0001$ ), HBB (4.1-fold, $\mathrm{p}<0.0001)$, HBD (7-fold, $\mathrm{p}<0.0001$ ), HBG1 (2.8-fold, $\mathrm{p}<0.001$ ), HBG2 (5.9-fold, $\mathrm{p}<0.0001$ ) and EPOR (2.6fold, $\mathrm{p}<0.001$ ) (Figure 1B, Supplementary Table S1). Gene set enrichment analysis focusing on genes known to be involved in erythroid differentiation showed a highly significant negative enrichment in VENTX overexpressing cells compared to the empty vector control (Figure 1C). Of note, around every $10^{\text {th }}$ gene of our data set overlapped with proteins expressed during erythroid differentiation as recently shown by quantitative mass spectrometry to determine the absolute proteome composition of human erythroid progenitors throughout the differentiation process (Supplementary Table S3) [6].

As we saw suppression of genes driving erythroid maturation, we tested first the expression of VENTX in the human primitive erythroblastic cell line HEL compared to other myeloblastic cell lines and normal erythroid cells: of note, highest expression was seen in HEL with a significant and 2.8-fold higher expression than in HL60 cells $(\mathrm{p}<0.001)$. Furthermore, HEL expressed VENTX 2.2-fold and 2.3-fold higher than normal highly purified Glycophorin A positive peripheral blood or $\mathrm{BM}$, respectively $(\mathrm{p} \leq 0.001)$ (Figure $2 \mathrm{~A})$. In line with data from primary AML samples [5], there was high expression in the $\mathrm{t}(8 ; 21)$ positive cell lines Kasumi-1 and SKNO-1 (Figure 2A). Analyses were extended to primary erythroleukemias (AML M6) and polycythemia vera patient samples, documenting high expression of VENTX in clear contrast to PML-RAR $\alpha$ positive AML, which did not show any detectable expression of VENTX as well as in contrast to $\mathrm{CD} 34^{+}$progenitor cells from normal bone marrow (Figure 2B, Table 1). To test whether expression levels of VENTX correlate with promoter methylation, DNA methylation of a total of 59 AML patients (54 normal karyotype (CN) AML samples, five samples with $\mathrm{t}(8 ; 21))$ was quantified by MassARRAY technology in comparison to normal CD34-enriched cord blood and $\mathrm{PB}$ of healthy individuals. A wide range of mean amplicon DNA methylation levels ( $4 \%$ to $86 \%$ ) was observed in the set of 54 AML samples with normal karyotype for amplicon 1 versus low DNA methylation levels $(10 \%$ to $21 \%$ ) in hematopoietic progenitor cells from cord blood and in sorted subfractions from peripheral blood $(10 \%$ to $19 \%)$. The $\mathrm{t}(8 ; 21)$ positive AML samples did not cluster separately at the amplicon 1 region but exhibited overall low DNA methylation levels (7\% to 20\%) (Supplementary Figure S2A-S2C).

Expression levels of VENTX were compared to DNA methylation in 8 NPM1 mutated patient samples (Table 1) as well as in sorted $\mathrm{CD}^{+}, \mathrm{CD}^{+} 4^{+}, \mathrm{CD}^{2} 5^{+}$, $\mathrm{CD}_{1} 9^{+}$and $\mathrm{GlyA}^{+}$subfractions from $\mathrm{PB}$ and $\mathrm{CD} 34^{+} \mathrm{CD} 38^{-}$, $\mathrm{CD} 34^{+} \mathrm{CD} 38^{+}, \mathrm{CD} 34^{-} \mathrm{CD} 38^{+}$subpopulations from $\mathrm{CB}$, respectively. However, there was no significant correlation between the VENTX expression and the level of DNA methylation of amplicon 1 and amplicon 2 in all cell populations tested (data not shown).

To evaluate, whether leukemic cells depend on VENTX expression, the impact of shRNA mediated depletion of VENTX on growth of HEL cells was tested: knockdown of VENTX expression by $98.85 \%$ and $99.43 \%$ for shVENTX_73 and shVENTX_77, respectively, 


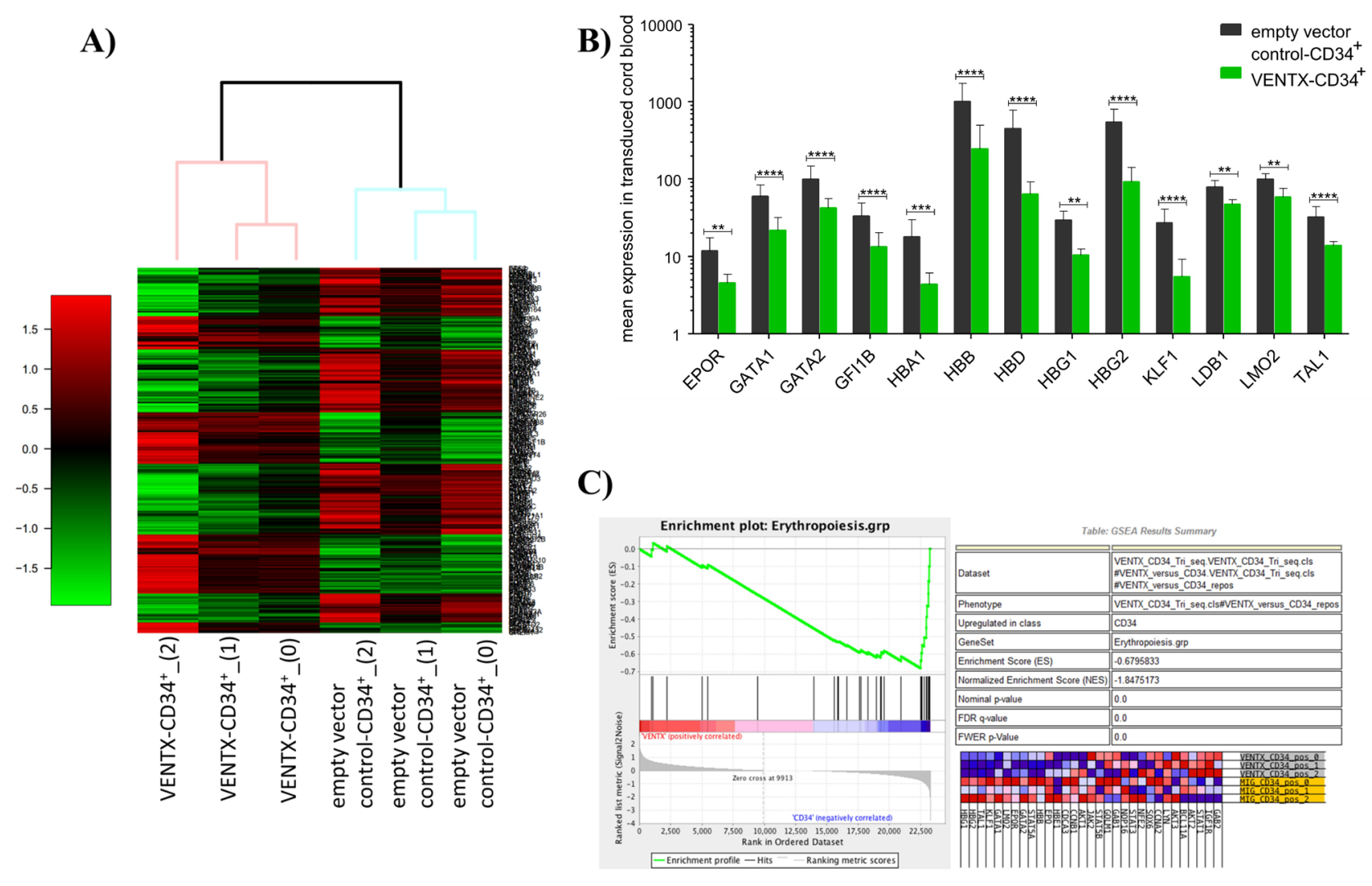

Figure 1: A. Heatmap of differentially expressed genes as determined by RNA-seq between CD34 ${ }^{+}$CB cells overexpressing VENTX compared to the empty vector control $(n=3)$. B. Differentially expressed genes transcription factors, which are known to play a role in erythroid development. $* * * *: p<0.0001, * * *: p \leq 0.0001, * *: p \leq 0.001$. C. Gene set enrichment analysis of genes involved in erythropoietic differentiation.

A)

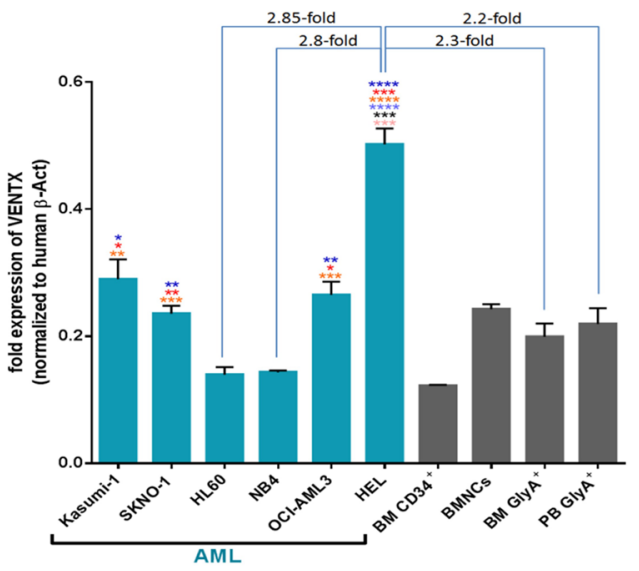

B)

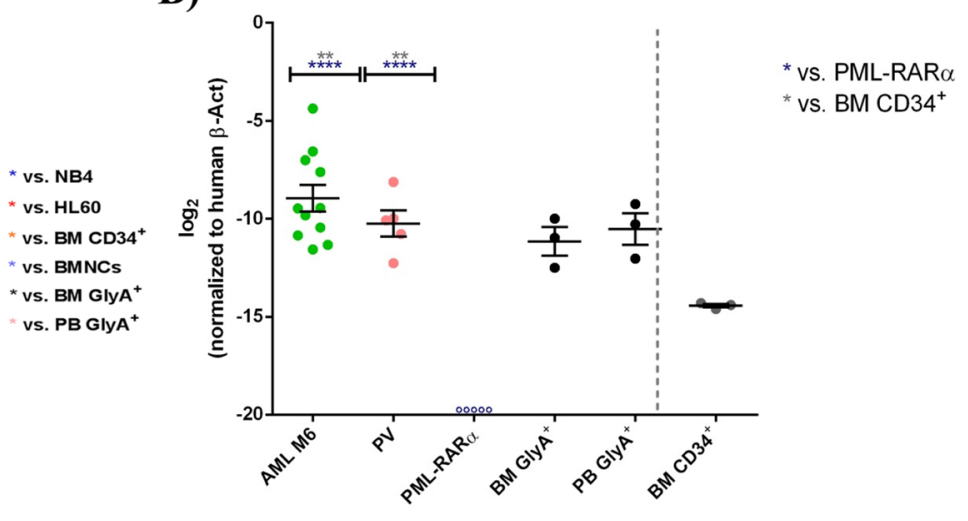

Figure 2: A. Quantitative expression of VENTX in different AML cell lines compared to BM CD34 $/ \mathrm{BMNCs}_{\mathrm{BM}} \mathrm{GlyA} / \mathrm{PB}$ GlyA $\mathrm{B}^{+}$. All expression analyses were performed by TaqMan ${ }^{\circledR}$ qRT-PCR with (+)RT and (-)RT reaction samples. Fold expression values were obtained by normalizing the expression of the gene of interest (VENTX) to the endogenous human $\beta$-actin ( $\beta$-Act). Bars are showing the average fold expression \pm SEM. *: $\mathrm{p} \leq 0.05, * *: \mathrm{p} \leq 0.001, * * *: \mathrm{p} \leq 0.0001, * * * *: \mathrm{p}<0.0001$. B. Mean Quantitative expression of VENTX AML M6 and PML-RAR $\alpha$ positive AML samples compared to Glycophorin A from BM/PB and CD34 bone marrow cells. All expression analyses were performed by TaqMan ${ }^{\circledR}$ qRT-PCR with $(+)$ RT and (-)RT reaction samples. $\log _{2}$ fold expression values were obtained by normalization of the expression of the gene of interest (VENTX) to the endogenous human $\beta$-actin. Bars are showing the $\log _{2}$ fold expression \pm SEM. **: $\leq 0.001$ and $* * * *: \mathrm{p}<0.0001$. $\circ$ indicates no detectable expression for 5 individual samples of PML-RAR $\alpha$ positive AML cases (for up to 37 cycles). 
Table 1: Patients' characteristics

\begin{tabular}{|c|c|c|c|c|c|}
\hline Patient no. & Diagnosis & Gender & Age & Karyotype & Other relevant markers \\
\hline 1 & AML M6a & M & 77 & $\begin{array}{c}\text { 46,XY,del(5)(q22q34), }+8, \operatorname{dic}(15 ; 17) \\
(\mathrm{p} 11 ; \mathrm{p} 11), \operatorname{der}(20 ; 21)(\mathrm{p} 10 ; \mathrm{q} 10),+\operatorname{der}(20 ; 21) \\
(\mathrm{p} 10 ; \mathrm{q} 10)[16]\end{array}$ & DNMT3A, TP53 \\
\hline 2 & AML M6a & M & 48 & $\begin{array}{c}\text { 46,XY,del(11)(p11p14) [11] } \\
46, \mathrm{XY}[9]\end{array}$ & none \\
\hline 3 & AML M6 & M & 74 & $\begin{array}{c}48, \mathrm{XY},+8,+8[4] \\
48, \mathrm{XY}, \operatorname{der}(6) \mathrm{t}(6 ; 6)(\mathrm{p} 25 ; \mathrm{q} 12),+8,+8[15] \\
46, \mathrm{XY}[1]\end{array}$ & DNMT3A, RUNX1, TP53 \\
\hline 4 & AML M6 & $\mathrm{F}$ & 81 & $\begin{array}{c}46, \mathrm{XX}, \mathrm{t}(4 ; 10)(\mathrm{q} 13 ; \mathrm{p} 12)[3] \\
45, \mathrm{XX}, \mathrm{t}(4 ; 10)(\mathrm{q} 13 ; \mathrm{p} 12), \operatorname{del}(5)(\mathrm{q} 31 \mathrm{q} 35),-7[3] \\
46, \mathrm{XX}[4]\end{array}$ & $\begin{array}{l}\text { TET2, } \\
\text { TP53 }\end{array}$ \\
\hline 5 & AML M6 & M & 71 & $\begin{array}{c}47, \mathrm{XY},+8[10] \\
46, \mathrm{XY}[10]\end{array}$ & $A S X L 1$ \\
\hline 6 & AML M6 & $\mathrm{F}$ & 38 & $46, X X$ & $\begin{array}{c}\text { ASXL1, } \\
\text { FLT3-ITD, NPM1 mut }\end{array}$ \\
\hline 7 & $\begin{array}{l}\text { AML M6: } \\
\text { tAML }\end{array}$ & $\mathrm{F}$ & 59 & $\begin{array}{c}92-96, \mathrm{XXX},-\mathrm{X}, 2 \mathrm{xadd}(4)(\mathrm{q} 35) \\
-7,+? 12,+22,+1-3 \mathrm{mar}\end{array}$ & TET2 \\
\hline 8 & $\begin{array}{l}\text { AML M6: } \\
\text { AML }\end{array}$ & M & 56 & $\begin{array}{l}\text { 46,XY,del(20)(q11) [5] } \\
\text { 46,XY [12] }\end{array}$ & $\begin{array}{l}\text { ASXL1, } \\
\text { IDH2, } \\
\text { MLL-PTD }\end{array}$ \\
\hline 9 & $\begin{array}{l}\text { AML M6: } \\
\text { sAML }\end{array}$ & $\mathrm{F}$ & 57 & $48, \mathrm{XX},+8,+19$ & TET2 \\
\hline 10 & AML M6 & $\mathrm{F}$ & 42 & $46, X X, \operatorname{inv}(9)(p 11 q 13) c$ & $\begin{array}{l}\text { IDH1, } \\
\text { NPM1 mut, } \\
\text { WT1 }\end{array}$ \\
\hline 11 & AML & M & 75 & $\begin{array}{c}45, X,-Y[16] \\
46, X Y[4]\end{array}$ & FLT3-ITD, NPM1 mut \\
\hline 12 & AML & $\mathrm{F}$ & 45 & $46, \mathrm{XX}[20]$ & NPM1 mut \\
\hline 13 & AML & M & 74 & $46, \mathrm{XY}[20]$ & FLT3-TKD, NPM1 mut \\
\hline 14 & AML & M & 46 & $46, X Y[20]$ & FLT3-ITD, NPM1 mut \\
\hline 15 & AML & $\mathrm{F}$ & 27 & $46, \mathrm{XX}[21]$ & NPM1 mut \\
\hline 16 & AML & $\mathrm{F}$ & 46 & $\begin{array}{l}46, X X, \operatorname{del}(9)(q 13 q 22)[10] \\
46, X X[10]\end{array}$ & NPM1 mut \\
\hline 17 & AML & $\mathrm{F}$ & 40 & $46, \mathrm{XX}[21]$ & FLT3-TKD, NPM1 mut \\
\hline 18 & AML & $\mathrm{F}$ & 49 & $46, \mathrm{XX}[23]$ & FLT3-ITD, NPM1 mut \\
\hline 19 & PV & $\mathrm{F}$ & 70 & $46, \mathrm{XX}[18]$ & $J A K 2$ \\
\hline 20 & PV & M & 81 & $46, \mathrm{XY}[20]$ & $\begin{array}{l}\text { DNMT3A, } \\
\quad J A K 2\end{array}$ \\
\hline 21 & PV & M & 60 & $46, \mathrm{XY}[20]$ & $J A K 2$ \\
\hline 22 & PV & $\mathrm{F}$ & 65 & $46, \mathrm{XX}[21]$ & $\begin{array}{l}A S X L 1, \\
J A K 2\end{array}$ \\
\hline 23 & PV & M & 76 & $46, \mathrm{XY}[20]$ & $J A K 2$ \\
\hline
\end{tabular}


resulted in a mean reduction of cell growth of $81 \%$ (76\%-84\%) and 95\% (91\%-98\%) after 6 days in liquid culture $(n=3)$ (Figure 3). We extended these analyses to other leukemic cell lines such as K562 and OCIAML3 cell lines. Similar findings were detected, when VENTX was knocked down in these cell lines with a significant reduction in cell proliferation, colony growth in methylcellulose, as well as survival and engraftment levels in NSG mice (for OCI-AML3) (data not shown). The efficiency of the shRNA mediated knockdown of VENTX on the protein level was measured after overexpression of VENTX in HEL cells by intracellular staining. As shown in Supplementary Figure S3 we could demonstrate, that knockdown of VENTX resulted in a decrease of VENTX protein as determined by a weaker fluorescent signal.

We performed an Annexin V staining and a BrdU assay to evaluate, whether cell cycle arrest, apoptosis or senescence might contribute to the oncogenic cooperativity in the AML1-ETO mouse model. Knockdown of VENTX lead to a 2.4-fold increase of the proportion of non-cycling cells as compared to the scrambled control arm. Using the Annexin V staining, we did not detect an increase of early or late apoptotic cells when VENTX was knocked down (data not shown).

\section{VENTX expands the primitive erythroid compartment and causes acute leukemia in transplanted mice}

To extend analyses on the functional relevance of VENTX overexpression, the homeobox gene was constitutively expressed in mouse BM progenitor cells and transplanted into lethally irradiated mice. Of note, all transplanted mice $(n=18)$ showed an accumulation of blasts in the BM and infiltration in the spleen with undifferentiated and erythroid blasts (median 47\%, range 29\%-85\%). (Supplementary Table S4). 3 of 18 mice developed overt clinical disease and died after 153, 189 and 249 days, respectively (Figure 4A) with an infiltration of $29 \%, 85 \%$ and $60 \%$ blasts in the bone marrow, respectively. The blasts were mostly undifferentiated with a substantial proportion displaying an erythroblast phenotype $(24 \%, 95 \%$ and $55 \%$, respectively) (Figure 4B and Supplementary Table S4). Leukemias were readily transplantable in 13 of 19 mice tested with disease development after short latency (median 14 days, range 11-67 days) (Figure 4A) and high erythroblast counts in the bone marrow, spleen and peripheral blood in secondary mice (Supplementary Table S4, Figure 4B). These blasts lacked expression of myeloid markers and were highly positive for Ter119 (median $86.8 \%$, range $76.9-95.2 \%$ ) and partly CD71 (median 45\%, range $1-79.3 \%$ ) (Figure 4C and Supplementary Table S5). Histological analyses in VENTX diseased mice showed the presence of erythroblasts with the diagnosis of an erythroleukemia according to the Bethesda criteria for non-lymphoid hematopoietic neoplasms (Figure 4D) [7].

To confirm the leukemogenic potential of VENTX we co-expressed the homeobox gene with the fusion gene AML1-ETO in the bone marrow transplantation assay. The rationale for this was that we have seen high expression of VENTX in patients with AML1-ETO positive leukemia

\section{HEL VENTX-Knockdown}

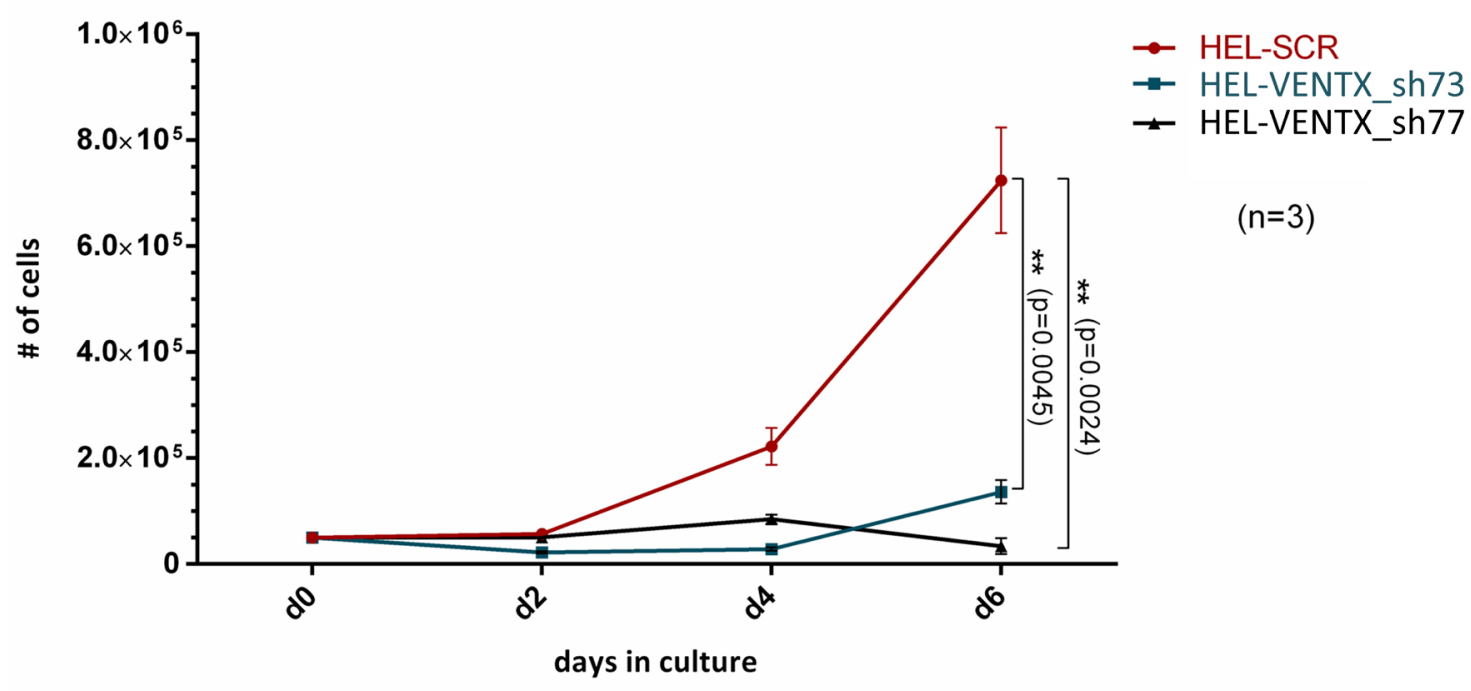

Figure 3: Cell proliferation in liquid expansion cultures from HEL cells after shRNA mediated knockdown of VENTX (shVENTX_73, shVENTX_77) compared to the scrambled control. Knockdown efficiency was $99 \%$ for both shRNA constructs ( $\mathrm{n}=3$ ). 
among others before [5]. Furthermore, it was previously shown, that AE is only able to induce leukemia with a leukemogenic partner in transplanted mice [8-10]. All mice $(n=20)$ transplanted with AE plus VENTX developed leukemia after a median of 337.5 days (range 19-403 days) post-transplantation (Figure 4A). Leukemias were characterized by high blast counts of mean $68.5 \%$ in the bone marrow (range 38 - 100\%) (Supplementary Table S4, Figure 5A) and expression of progenitor cell and myeloid markers: Sca- 1 (median $20.5 \%$, range 11.8 $32.4 \%$ ) and c-kit (median 8.5\%, range $2.9-78.5 \%$ ), Gr-1 (median 34.7\%, range 3.0 - 52.3\%) and Mac-1 (median $33.2 \%$, range 0-67.1\%) (Figure 5B, Supplementary Table S5). Surprisingly, myeloid blasts expressed CD71 in the bone marrow, which we did not see in our AML1-ETO bone marrow transplantation model overexpressing FLT3LM (Figure 5B) [8]. Strikingly, secondary diseased mice displayed partly large nodules consisting of erythroblasts extending to diffuse erythroblastic infiltration in the spleen in other mice. The white pulp was almost eradicated with few residual B220 and CD3 positive cells (Figure 5C).
Leukemias were readily transplantable in secondary $(n=14)$ and tertiary recipient mice $(n=9)$ (median 129 days, range 13 to 343 days for secondary and median 14 days, range 13 to 18 days for tertiary mice) (Figure 4A). BM of diseased mice displayed an infiltration of the bone marrow with CD71 (median 46.7\%, range 22.5 - 72\%) and CD36 (median $82 \%$, range $60.2-90.7 \%$ ) expressing cells. To exclude retroviral insertional mutagenesis in VENTX and AE/VENTX induced leukemias, integration sites were sequenced: there was one, but not recurrent site enlisted in the retroviral tagged cancer genes database (RTCGD) (Supplementary Table S6). Leukemic cells originating from diseased AE/VENTX mice showed 250-fold $( \pm 30)$ and 713-fold $( \pm 90)$ increased colony formation and replating capacity ex vivo, respectively $(\mathrm{p}<0.05)$, compared to BM cells isolated from mice transplanted with cells expressing AE alone (Figure 6). Cytospins of generated colonies showed blast morphology with $>50 \%$ of blast cells/blasts. Cells from a secondary AE/VENTX mouse showed permanent but growth factor (rmIL3, rmSCF, rmIL6) dependent cell growth, blast morphology, and high
A)

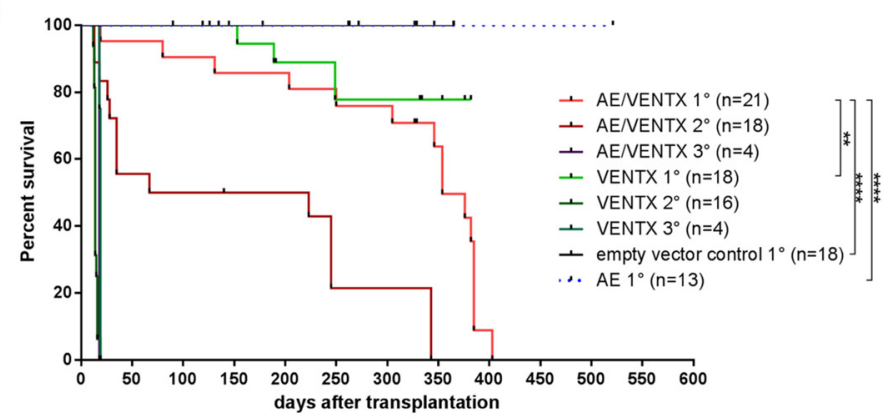

B)

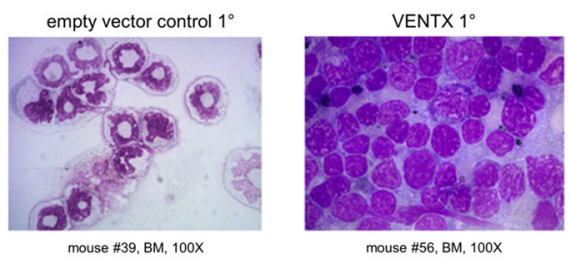

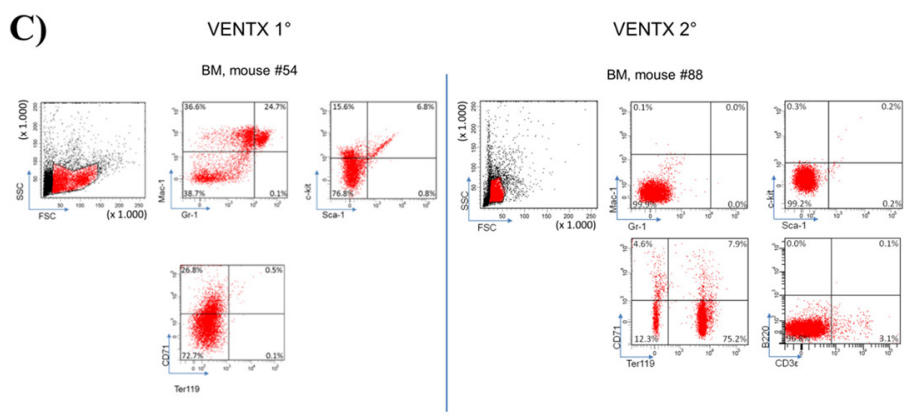

D)

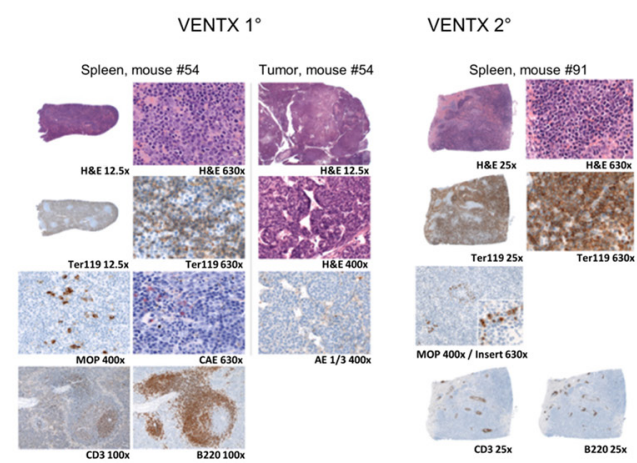

Figure 4: A. Kaplan-Meier survival curves of mice transplanted with 5-FU stimulated transduced BM cells expressing AML1ETO+VENTX [AE/VENTX $1^{\circ}$ ] $(\mathrm{n}=20)$, VENTX [VENTX $\left.1^{\circ}\right](\mathrm{n}=18)$, empty vector control $(\mathrm{n}=18)$ and AML1-ETO $\left[\right.$ AE $1^{\circ}$ ] $(\mathrm{n}=15)$. Secondary and tertiary transplantations are shown for leukemic mice: AE/VENTX $2^{\circ}(\mathrm{n}=14)$, AE/VENTX $3^{\circ}(\mathrm{n}=9)$, VENTX $2^{\circ}(\mathrm{n}=19)$, $\operatorname{VENTX} 3^{\circ}(\mathrm{n}=4)$. AE/V $1^{\circ}-\mathrm{V} 1^{\circ} \mathrm{V}=\operatorname{VENTX}: * *, \mathrm{p}=0.0011 ; \mathrm{AE} / \mathrm{V} 1^{\circ}-$ empty vector control $1^{\circ}: * * * *, \mathrm{p}<0.0001 ; \mathrm{AE} / \mathrm{V} 1^{\circ}-\mathrm{AE} 1^{\circ}$ : $* * * *, \mathrm{p}<0.0001 ; \mathrm{V} 1^{\circ}$ - empty vector control $1^{\circ}$ : n.s. (n.s. = not significant); V $1^{\circ}-\mathrm{AE} 1^{\circ}$ : ns; AE/V $2^{\circ}-\mathrm{V} 2^{\circ}$ : ns; AE/V $3^{\circ}-\mathrm{V} 3^{\circ}: \mathrm{ns}$. B. Representative cytomorphological analyses of bone marrow of a diseased VENTX transplanted $1^{\circ}$ mouse compared to an empty vector control mouse. C. Representative flow cytometric analysis of a primary VENTX recipient mouse (left side) and a secondary VENTX recipient mouse (right side) D. Histological analysis of primary (left side) and secondary (right side) VENTX recipient mice. 
expression of CD71 (87.4\%), whereas Ter119 as well as Gr-1, Mac-1, Sca-1 and c-kit were virtually not expressed, corresponding to the immunophenotype of erythroid precursors [11] (data not shown). This cell population maintained its leukemogenicity in vivo and rapidly induced leukemia in transplanted mice $(n=3)$ within 14 days (13 - 14 days). Engrafted cells expressed Ter119 and maintained the erythroblastic phenotype (Supplementary Figure S4A-S4B). When placed in methylcellulose assay cells from this cell line generated undifferentiated serially replatable colonies, which expressed CD71 (85.6\%) and were negative for Sca-1, c-kit, Ter119, Gr-1, Mac-1 (data not shown).

\section{DISCUSSION}

This report documents for the first time that aberrant expression of the homeobox gene VENTX contributes to the development of acute myeloid leukemia and by this extends the list of non-clustered homeobox genes with leukemogenic potential. We reported previously that
VENTX is highly expressed in various subtypes of AML, but failed to prove on a functional level that the gene is directly involved in myeloid leukemogenesis, possibly also because of the limitations of xenograft models to mirror the effect of oncogenes to a full extent [5]. In our current bone marrow transplantation model, aberrant expression of VENTX was able to induce acute leukemia in a part of transplanted mice after long latency, indicating that VENTX needs collaborative partners to exert its full leukemogenic potential. One of the candidates for such an oncogenic partner is the most frequent fusion gene in human AML, AML1-ETO, as we had seen high expression of VENTX in patients with AML1-ETO positive AML [5]. AML1-ETO is able to increase self-renewal of hematopoietic stem- and progenitor cells, but is not overt leukemogenic as shown in several independent mouse and human experimental models [8-10, 12-15]. VENTX induced AML in all transplanted mice in collaboration with AML1-ETO, characterizing VENTX as a novel collaborative partner of AML1-ETO. With this, VENTX is among the first homeobox genes shown to cooperate with AML1-ETO, as we could just recently demonstrate
A)

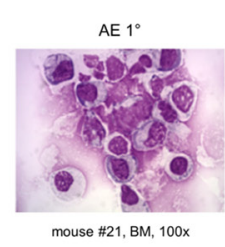

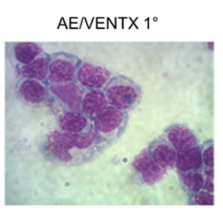

mouse \#9, BM, 100x

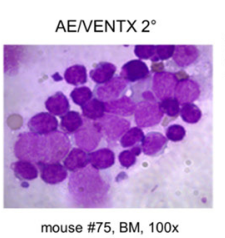

B)

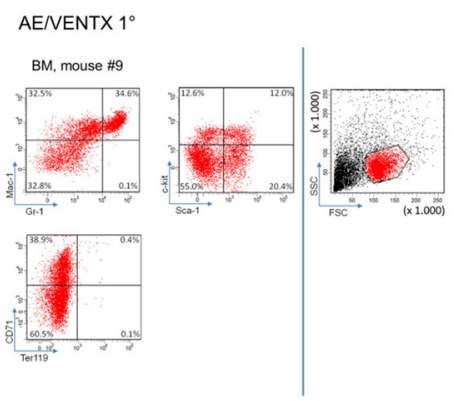

AENENTX $2^{\circ}$

$B M$, mouse \#77

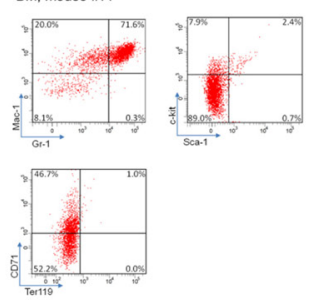

C)

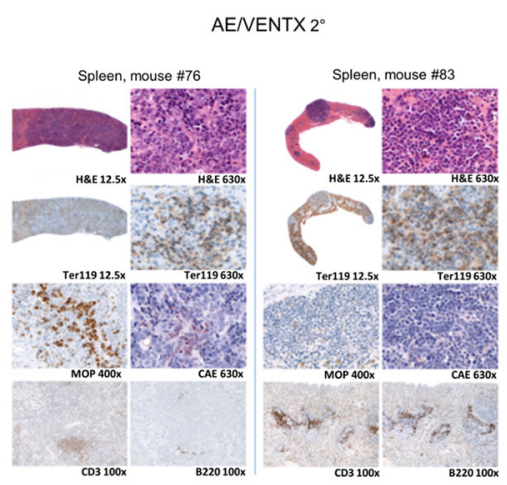

Figure 5: A. Representative cytomorphological analysis of bone marrow cytospins of diseased mice as indicated (AE/VENTX $1^{\circ}$ and $2^{\circ}$ ) compared to a representative non-leukemogenic AE $1^{\circ}$ mouse. B. Representative flow cytometric analysis of a primary AE/VENTX recipient mouse (left side) and a secondary AE/VENTX recipient mouse (right side) C. Histological analysis of two secondary transplanted AE/VENTX mice, showing erythroblasts in the spleen of the diseased animals. 
that the TALE homeobox gene MEIS2 collaborates with the fusion in inducing AML [16]. It also demonstrates that the transcription factor AML1-ETO can collaborate with its own class as VENTX is a bona fide transcription factor. Following the classical two hit model proposed previously $[17,18]$, leukemic transformation depends on two factors, one conferring self-renewal and the other one impairing differentiation of hematopoietic progenitor cells. AML1ETO has a well-established function as a factor increasing self-renewal [19]. Although the two-hit model is surely an oversimplification of complex AML biology, it would require that VENTX impairs differentiation. Indeed, the most surprising observation was that VENTX induced expansion of primitive erythroid cells up to erythroblastic leukemia on its own and induced AML with partly erythroid features together with AML1-ETO. This went along with suppression of several erythroid master regulators of erythroid differentiation, resulting in a highly significant negative enrichment score for expression of these factors in VENTX overexpressing cord blood cells. We had not seen this erythroblastic phenotype in our own
AML1-ETO - FLT3-LM model or from the perspective of homeobox genes in our AML models depending on homeobox gene expression [4, 8, 20, 21]. However, it has been described previously, that AML1-ETO positive leukemias show an impairment in erythroid differentiation [22-25]. This might indicate, that VENTX impairs in particular differentiation along the erythroid line in hematopoietic progenitor cells enforced to self-renew by the AML1-ETO fusion. In line with this overexpression of VENTX in $\mathrm{CD}^{+} 4^{+}$cord blood cells resulted in a nearly complete block of erythroid differentiation with an $81 \%$ reduction of the number of BFU-E as previously reported by us [5]. Our data demonstrate that aberrant expression of VENTX has leukemogenic potential. Importantly, Gao et al recently described that VENTX can act as a potential tumor suppressor gene in solid cancer cell lines originating from lung and colon cancer [26]. Furthermore, the same group previously demonstrated that VENTX is able to impair cell growth in chronic lymphocytic leukemia [27]. All these data indicate that the function of VENTX largely depends on the cellular context and that VENTX can act

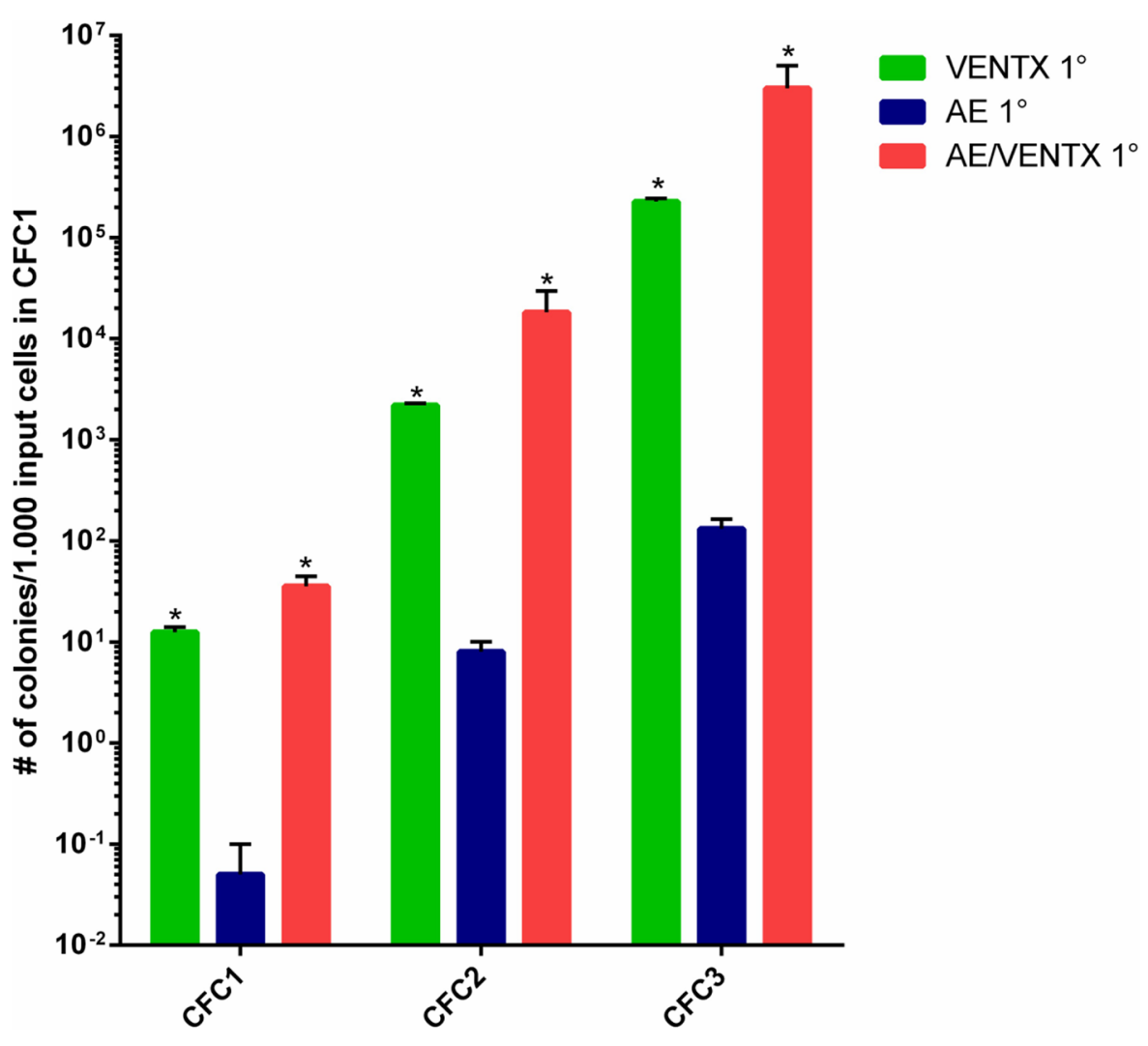

Figure 6: Ex vivo colony forming cell assay (CFC1) and re-plating assays (CFC2, CFC3) of leukemic cells isolated from mice transplanted initially with 5-FU BM cells transduced with the different constructs as indicated. Results are means $\pm \mathrm{SEM}$. The number of CFC refers to 1000 input cells in the primary $\mathrm{CFC}$ assay. For $2^{\circ}$ and $3^{\circ} \mathrm{CFC}$ assay also the $\mathrm{CFC}$ numbers are indicated per initially plated 1000 cells for the primary $\mathrm{CFC}(*: \mathrm{p} \leq 0.05)$. 
as tumor suppressor and as oncogene. This has to be taken into account, if therapeutic approaches are considered which are targeting VENTX dependent functions or VENTX itself.

Taken together, our data extend the number of homeobox genes critically involved in myeloid leukemogenesis, but also underline that the role of this gene family in tumorigenesis can critically depend on the cancer subtype.

\section{MATERIALS AND METHODS}

\section{Human samples and cell lines}

Mononuclear cells isolated from diagnostic bone marrow (BM) or peripheral blood (PB) from 28 adult patients were analyzed for their VENTX expression: $\mathrm{n}=10$ for AML M6, $\mathrm{n}=5$ for polycythaemia vera (PV) and $n=5$ for PML-RAR $\alpha, n=8$ for NPM1 mutated AML. CD34 ${ }^{+}$bone marrow mononuclear cells (BMNCs) and CD34 ${ }^{+}$cord blood (CB) cells (both from Lonza, Cologne, Germany) ( $n=5$ and $n=3)$ as well as sorted subfractions from peripheral blood and bone marrow from healthy individuals were taken as controls [5]. Cytomorphological, cytogenetic and molecular analyses were performed in all cases as described. Cases were classified according to the French-American-British criteria and the World Health Organization classification (Table 1) [28, 29]. The study was approved by the ethics committees of all participating institutions, and informed consent was obtained from all patients before they entered the study in accordance with the Declaration of Helsinki (http://www.wma.net/ en/30publications/10policies/b3/index.html).

All cell lines used were obtained from DSMZ, Braunschweig, Germany. Original stocks were frozen down and all experiments were performed with aliquots from the original stock with less than 6 months propagation in vitro. DSMZ guarantees originality of cell lines by comprehensive molecular testing e.g. by polymerase chain reaction (PCR) amplification of eight highly polymorphic microsatellite STR loci, using the uniqueness of DNA profiles in an STR database. For RNA-Seq experiments, human cord blood cells were retrovirally transduced with VENTX or an empty vector control as described previously [5].

\section{Quantification of VENTX expression}

Total RNA was isolated using the Direct-zol ${ }^{\mathrm{TM}}$ Kit (Zymo Research, Freiburg, Germany) and TRIzol ${ }^{\circledR}$ Reagent. To avoid genomic DNA contamination all RNA samples were treated with DNaseI enzyme according to the manufacturer's instructions (ThermoFisher, Darmstadt, Germany). cDNA was prepared using random hexamer primers (Primescript RT-PCR kit; TAKARA Clontech, Saint-Germain-en-Laye, France) according to the manufacturer's instructions. For endogenous control, the human $\beta$-actin gene ( $\beta$-Act) was used. Reactions were run in duplicates or triplicates with $50 \mathrm{ng}$ cDNA input material per detection well in a total reaction volume of $20 \mu \mathrm{l}$ on an ABI PRISM 7900 HT Fast Real-Time PCR Sequence Detection System (ThermoFisher). Expression of VENTX was assayed by TaqMan ${ }^{\circledR}$ quantitative realtime polymerase chain reaction (qRT-PCR) in the HEL erythroid leukemia as well as Kasumi-1, SKNO-1, HL60, NB4 and OCI-AML3 cell lines and in patient samples with AML M6 as well as polycythaemia vera and compared to patient samples with PML-RAR $\alpha$ and sorted subpopulations of peripheral blood and BM from healthy donors. For VENTX the human TaqMan ${ }^{\circledR}$ probe Hs00797729_s1 was used (ThermoFisher). Primer and probes for analyzing the expression of VENTX were selected specifically for that gene, in order to prevent amplification of known VENTX pseudogenes. The relative expression of each gene was determined by calculating fold change $\left(2^{-\Delta \mathrm{Ct}}\right)$ to the housekeeping gene $(\beta-A c t)$.

\section{LM-PCR}

For the linker-mediated PCR (LM-PCR), integrated Yellow and Green Fluorescent Protein (YFP and GFP) and flanking genomic sequences were amplified and then isolated using a modification of the bubble LMPCR strategy [30]. Aliquots of the cell lysates from leukemic mouse bone marrow (BM) and spleen (SP) were digested with PstI (New England Biolabs Inc., Frankfurt a.M, Germany), and the fragments were ligated overnight at $16^{\circ} \mathrm{C}$ to a double-stranded bubble linker (5'CTCTCCCTTCTCGAATCGTAACCGTTCGTACG AGAATCGCTGTCCTCTCCTCCTGCA3' and 5'GG AAGGAGAGGACGCTGTCTGTCGAAGGTAAGG AACGGACGAGAGAAGGGAGAG3'). Next, a first PCR (PCR-A) was performed on $10 \mu$ ( one-tenth) of the ligation product using a linker specific Vectorette primer (5'CGAATCGTAACCGTTCGTACGAGAATCGCT3') (ThermoFisher) and a GFP/YFP-specific primer (GFP/ YFP-A: 5'ACTTCAAGATCCGCCACAAC3') under the following conditions: 1 cycle of $94^{\circ} \mathrm{C}$ for 2 minutes, 30 cycles of $94^{\circ} \mathrm{C}$ for 30 seconds and $65^{\circ} \mathrm{C}$ for 1 minute, and 1 cycle of $72^{\circ} \mathrm{C}$ for 2 minutes. The bubble linker contains a 30-nucleotide non-homologous sequence in the middle region that prevents binding of the linker primer in the absence of minus strand generated by the LTRspecific primer. A $1 \mu \mathrm{l}$-aliquot of the PCR-A reaction (onefifteenth) was then used as a template for a second, nested PCR (PCR-B) using an internal GFP/YFP-specific primer (GFP/YFP-B: 5'ACATGGTCCTGCTGGAGTTC3') and the same linker-specific Vectorette primer as was used in PCR-A, with the following conditions: 1 cycle of $94^{\circ} \mathrm{C}$ for 2 minutes, 35 cycles of $94^{\circ} \mathrm{C}$ for 60 seconds and $72^{\circ} \mathrm{C}$ for 1 minute, and 1 cycle of $72^{\circ} \mathrm{C}$ for 2 minutes. $100 \mu \mathrm{l}$ of the final PCR-B product were electrophoresed using a 
$2 \%$ agarose tris-acetate EDTA gel. Individual bands were excised and purified using the illustra GFX PCR DNA and Gel Band Purification Kit (GE Healthcare Life Sciences, Freiburg, Germany). The eluted samples were sequenced with the Vectorette primer by LGC genomics (Berlin, Germany). The sequences were then aligned using BLAST (www.ncbi.nlm.nih.gov/BLAST/) to identify the genomic location of the flanking sequences. Identified genomic loci were screened using the retroviral tagged cancer genes database (RTCGD).

\section{Retroviruses and plasmids}

MSCV based retroviral vectors were used for overexpression of AML1-ETO (AE) and VENTX. The VENTX cDNA was provided by Paul Moretti (Institute of Medical and Veterinary Science, Adelaide, Australia) and subcloned into the retroviral pMSCV-IRES-YFP vector, as previously described [31]. The $A E$ construct was subcloned into the GFP vector. As control, an empty vector (MSCV vector carrying only the IRES and GFP or YFP-cassette) was used (empty vector control).

\section{Transduction and BM transplantation}

Stable packaging cell lines were generated for the different constructs and used for BM experiments as reported previously [21]. 5-FU BM was transduced with empty vector (control), VENTX, AE alone or with AE plus VENTX (AE/VENTX) in four, six, five and four independent experiments, respectively. Successfully transduced BM cells were transplanted unsorted into lethally irradiated (12 Gy) recipient mice. Transduction efficiency was on average $12.8 \%(2.2 \%-19.4 \%)$ or $0.7 \%$ (0.1\%-1.2\%) for VENTX alone and AE/VENTX doubletransduced cells, respectively, $6.8-40.1 \%$ for the empty vector control and $26.1 \%(4.5 \%-36.9 \%)$ for AE. As donor mice $>12$-week-old (C57Bl/6Ly-Pep3b x C3H/HeJ) F1 (PepC3) mice, as recipients $>12$-week-old $(\mathrm{C} 57 \mathrm{Bl} / 6 \mathrm{~J} \mathrm{x}$ $\mathrm{C} 3 \mathrm{H} / \mathrm{HeJ}) \mathrm{F} 1$ (B6C3) mice were used. The number of transplanted cells ranged from $4.5 \times 10^{5}$ to $3.7 \times 10^{6}$ cells per mouse for VENTX and from $4 \times 10^{4}$ to $2 \times 10^{6}$ cells per mouse for AE/VENTX (for AE $2.1 \times 10^{5}-2 \times 10^{6}$ cells per mouse, for the empty vector control (ctrl.) $1.8 \times 10^{6}-$ $3.3 \times 10^{6}$ cells per mouse). For secondary transplantation between $8.7 \times 10^{4}$ (plus once with $2.1 \times 10^{5}$ helper cells) to $1 \times 10^{6}$ unsorted cells from primary diseased mice were transplanted per mouse, for tertiary transplantation the number of transplanted cells per mouse ranged from 0.5 to $0.6 \times 10^{6}$ unsorted BM cells from primary diseased animals.

CD34 positive human cord blood cells were retrovirally transduced with VENTX and the empty vector control as described previously [5]. After 48 hours successfully transduced cells were highly purified and subjected to RNASeq analysis.

\section{shRNA mediated VENTX knockdown}

For stable shRNA mediated knockdown of endogenous VENTX genes, pLKO.1 based lentiviral vectors were used: pLKO.1 empty vector (SHC001), pLKO.1 scrambled (SHC002), pLKO.1shVENTX_77 (TRCN0000015977, GenBank accession no. NM_014468.3), pLKO-1-shVENTX_73 (TRCN0000015973) (all obtained from Sigma-Aldrich, Munich, Germany). shVENTX_77 and shVENTX_73 oligonucleotides were cloned into the pGreenPuro vector (System Biosciences, California, USA). shRNA mediated knockdown in human cell lines was achieved following the experimental procedure as described previously [5].

For lentiviral transduction, Lenti-X ${ }^{\mathrm{TM}} 293 \mathrm{~T}$ (Clontecth, \#632180) cells were transiently transfected with $\mathrm{CaCl}_{2}$. Lenti-X ${ }^{\mathrm{TM}} 293 \mathrm{~T}$ cells were cultured in a 10 $\mathrm{cm}$ dish to a confluency of $70 \%$. Virus containing medium (VCM) was collected and filtered through a $0.45 \mu \mathrm{m}$ filter. VCM was concentrated with an ultracentrifuge 1:100.

\section{Intracellular staining}

For intracellular staining HEL cells were transduced in order to overexpress an HA-tagged construct of VENTX. Afterwards an shRNA mediated knockdown of VENTX was performed. 75,000 of these cells were spun with $450 \mathrm{rpm}$ for $10 \mathrm{~min}$ onto microscope slides. Then, cells were fixed with 4\% PFA for $10 \mathrm{~min}$ at RT, followed by a washing step in PBS. In order to permeabilize the cells, cells were treated with $0.1 \%$ Triton-X 100 for $5 \mathrm{~min}$ at RT. Afterwards cells were treated with precooled pure Ethanol (cooled to $-20^{\circ} \mathrm{C}$ ) for $15 \mathrm{~min}$ at $-20^{\circ} \mathrm{C}$, before they were washed with PBS and blocked with $10 \%$ BSA for $1 \mathrm{hr}$ at RT. After blocking, cells were washed in PBS and incubated with the primary antibody anti-HA, rabbit (Abcam, 1:300 dilution) for 2 hrs at RT. Then, cells were washed with PBS and stained with the fluorescent secondary antibody goat-anti-rabbit-Alexa Fluor 594(1:1000 dilution) for $1 \mathrm{hr}$ at RT in the dark. Then, cells were washed with PBS and nuclei were stained with DAPI (1:1000) for $3 \mathrm{~min}$ at RT. Cells were again washed with PBS and mounted with antifade fluorescent mounting medium and covered with a cover slip. Slides were analyzed with a fluorescent microscope.

\section{Colony forming cell (CFC) assay and cytospin}

Hematopoietic colony forming cell (CFC) assays were performed using methylcellulose supplemented with murine cytokines (MethoCult GF M3434, Stem Cell Technologies, Cologne, Germany) as previously described [21]. 7 days after setting up the CFC, number and morphology of the colonies were assessed. For testing the clonogenic potential of leukemic BM from diseased 
mice $1-3 \times 10^{4}$ cells per dish were plated for primary CFC and 500 to $5 \times 10^{3}$ cells for re-plating assays. For cytomorphological analyses by cytospin $0.1 \times 10^{6}$ cells were spun onto a microscope slide by a centrifugation step for $5 \mathrm{~min}$ at $350 \mathrm{rpm}$. The number of CFC for the first and second re-plating experiments was calculated for 1000 cells initially plated cells (CFC1), thereby accounting not only for the number of CFC per plated cell but also for the number of cells generated per CFC.

\section{Flow cytometric analysis}

Cells were stained according to standard protocols. Cells were resuspended in PBS and treated with $1 \%$ ammonium chloride solution (10 min on ice). $1 \times 10^{5}$ cells/FACS tube were resuspended in $100 \mu \mathrm{l}$ of PBS and incubated on ice for $10 \mathrm{~min}$ with a purified rat antimouse CD16/32 antibody (BioLegend, Fell, Germany) to block non-specific antibody binding. After blocking, cells were stained for $20 \mathrm{~min}$ on ice. The following antibodies were used for flow cytometric analyses of murine bone marrow cells and permanently growing cells of a diseased mouse: Ter119 and CD36 labeled with APC (both BioLegend), B220 and Ter119 labeled with eFluor450 (both eBioscience, Frankfurt, Germany), Mac-1 labeled with qDot605 (BioLegend). Antibodies labeled with Alexa Fluor 700 were used against the epitope of c-kit (eBioscience), Gr-1 was labeled with APC-Cy7 (both BioLegend), Sca-1 with PE-Cy5.5 (Caltag) and CD71 with PE-Cy7 (Becton Dickinson and BioLegend, respectively). Cells were analyzed using a FACS FORTESSA LSR II (Becton Dickinson, Heidelberg, Germany).

\section{BrdU staining}

BrdU staining was performed according to the manufacturer's instructions (BD Pharmingen BrdU Flow Kit, BrdU-APC). Briefly, 100,000 cells (HEL-SCR, HELshVENTX_73, HEL-shVENTX_77) were starved in RPMI supplemented with $1 \%$ FBS and $1 \%$ Pen/Strep for $16 \mathrm{hrs}$. Afterwards FBS was added in order to obtain a final concentration of $10 \% \mathrm{FBS}$ and cells were incubated in that medium for another $24 \mathrm{hrs}$. BrdU treatment was performed for $30 \mathrm{~min}$ at $37^{\circ} \mathrm{C}$.

\section{Annexin V staining}

Annexin $\mathrm{V}$ apoptosis assay was performed according to the manufacturer's instructions (BD, APC Annexin V apoptosis Detection Kit).

\section{Bisulfite conversion and quantitative DNA methylation analysis (MassARRAY)}

Bisulfite conversion and quantitative DNA methylation analysis (MassARRAY) was performed as described preciously [32]. Briefly, genomic DNA
(gDNA) of sorted subpopulations from peripheral blood and cord blood from healthy donors was isolated according to the manufacturer's instructions using the column based DNeasy Blood \& Tissue purification Kit (Quiagen, Hilden, Germany). Afterwards, gDNA samples were bisulfite-modified using the EZ DNA methylation kit (Zymo Research, Freiburg, Germany). The specific primer sequences used for PCR amplification are available upon request. The MassARRAY EpiTYPER Assay was performed at Sequenom Inc. (Hamburg, Germany) as described previously [33]. Amplicon 1 was located on chromosome 10:133237067-133237565, Amplicon 2 on chromosome 10: 133237570-133238054. The coordinates were based on genome version GRCh38/hg38 Dec 2013. After amplification, PCR products were transcribed in vitro before being cleaved by RNase A and subjected to matrix-assisted laser desorption/ionization time-of-flight mass spectrometry (MALDI-TOF MS). Methylation standards were used as controls and for normalizing data, while standards had $0 \%, 20 \%, 40 \%, 60 \%, 80 \%$, and $100 \%$ of methylated genomic DNA.

\section{RNA-Seq methods}

For cord blood experiments (VENTX, CD34 ${ }^{+}$) sequencing libraries were prepared using Illumina TruSeq ${ }^{\text {TM }}$ RNA Kit (Illumina, Inc.). All samples were run on the Illumina HiSeq2000 platform. The raw paired-end reads were adapter trimmed and quality filtered (phred score of $>20$ ) using the cutadapt wrapper trim galore [34]. Filtered sequences were aligned to the human hg19 RefSeq using tophat and differential expression analyses were performed using Cufflinks with downstream analysis in $\mathrm{R}$ and Bioconductor [35-37].

\section{Gene set enrichment analysis}

Gene Set Enrichment Analysis (GSEA) was performed using the GSEA tool from broad MIT [38], using the set of significantly differentially expressed genes from the RNA-Seq analysis generated from CB cells transduced with either VENTX or the empty vector control $(n=3$, respectively). GSEA focused on genes known to be involved in erythropoietic differentiation.

\section{Histopathology}

For histological analyses, sections of selected organs were prepared and stained using standard protocols as previously described $[4,8]$.

\section{Statistical analyses}

Data were evaluated using the $t$ test for independent samples. Differences with $p$ values less than 0.05 were considered to be statistically significant (* $\mathrm{p} \leq 0.05$; $* * \mathrm{p} \leq 0.001 ; * * * \mathrm{p} \leq 0.0001 ; * * * * \mathrm{p}<0.0001)$. Values 
mentioned are Mean \pm SEM. PRISM GraphPad PRISM ${ }^{\circledR}$ software, Prism 6 (Version 06.01) for Windows, Microsoft Excel 2010 was used to determine the correlation coefficients, Version 6.01 (La Jolla, California, USA) was used for the analysis and figures and FACSDiva 8.0 (Becton Dickinson) to analyze the FACS plots.

\section{ACKNOWLEDGMENTS}

The authors would like to thank all members of the Core Facility FACS, Core Facility Genomics of the University Ulm, H. Jumaa, E. Hobeika and M. Werner, Institute of Immunology of the University Ulm for technical support and the animal facility of the University Ulm for breeding and maintenance of the animals. The work was supported by a grant from the DFG (SFB 1074 project A6 to MFB and VPSR, project B3 to KD and $\mathrm{LB}$ and project $\mathrm{Z} 1$ to $\mathrm{CB}$ and MAM). LB was funded by the Heisenberg professorship from the German Research Association (DFG). EG was funded by the International Graduate School in Molecular Medicine Ulm, Ulm University. AT was supported by the Else-Kröner Forschungskolleg (EKF).

\section{CONFLICTS OF INTEREST}

The authors declare no conflicts of interest.

\section{GRANT SUPPORT}

This work was supported by the DFG (SFB 1074, project A6).

\section{REFERENCES}

1. Abramovich C, Humphries RK. Hox regulation of normal and leukemic hematopoietic stem cells. Curr Opin Hematol. 2005; 12:210-216.

2. Thorsteinsdottir U, Kroon E, Jerome L, Blasi F, Sauvageau G. Defining roles for HOX and MEIS1 genes in induction of acute myeloid leukemia. Mol Cell Biol. 2001; 21:224-234.

3. Rawat VP, Humphries RK, Buske C. Beyond Hox: the role of ParaHox genes in normal and malignant hematopoiesis. Blood. 2012; 120:519-527.

4. Rawat VP, Thoene S, Naidu VM, Arseni N, Heilmeier B, Metzeler K, Petropoulos K, Deshpande A, QuintanillaMartinez L, Bohlander SK, Spiekermann K, Hiddemann W, Feuring-Buske M, Buske C. Overexpression of CDX2 perturbs HOX gene expression in murine progenitors depending on its N-terminal domain and is closely correlated with deregulated HOX gene expression in human acute myeloid leukemia. Blood. 2008; 111:309-319.

5. Rawat VP, Arseni N, Ahmed F, Mulaw MA, Thoene S, Heilmeier B, Sadlon T, D'Andrea RJ, Hiddemann W, Bohlander SK, Buske C, Feuring-Buske M. The vent-like homeobox gene VENTX promotes human myeloid differentiation and is highly expressed in acute myeloid leukemia. Proc Natl Acad Sci U S A. 2010; 107:16946-16951.

6. Gautier EF, Ducamp S, Leduc M, Salnot V, Guillonneau F, Dussiot M, Hale J, Giarratana MC, Raimbault A, Douay L, Lacombe C, Mohandas N, Verdier F, Zermati Y, Mayeux P. Comprehensive Proteomic Analysis of Human Erythropoiesis. Cell Reports. 2016; 16:1470-1484.

7. Kogan SC, Ward JM, Anver MR, Berman JJ, Brayton C, Cardiff RD, Carter JS, de Coronado S, Downing JR, Fredrickson TN, Haines DC, Harris AW, Harris NL, Hiai H, Jaffe ES, MacLennan IC, et al. Bethesda proposals for classification of nonlymphoid hematopoietic neoplasms in mice. Blood. 2002; 100:238-245.

8. Schessl C, Rawat VP, Cusan M, Deshpande A, Kohl TM, Rosten PM, Spiekermann K, Humphries RK, Schnittger S, Kern W, Hiddemann W, Quintanilla-Martinez L, Bohlander SK, Feuring-Buske M, Buske C. The AML1-ETO fusion gene and the FLT3 length mutation collaborate in inducing acute leukemia in mice. J Clin Invest. 2005; 115:2159-2168.

9. Licht JD. AML1 and the AML1-ETO fusion protein in the pathogenesis of $\mathrm{t}(8 ; 21)$ AML. Oncogene. 2001; 20:5660-5679.

10. Wang YY, Zhao LJ, Wu CF, Liu P, Shi L, Liang Y, Xiong SM, Mi JQ, Chen Z, Ren R, Chen SJ. C-KIT mutation cooperates with full-length AML1-ETO to induce acute myeloid leukemia in mice. Proc Natl Acad Sci U S A. 2011; 108:2450-2455.

11. Boyer SW, Schroeder AV, Smith-Berdan S, Forsberg EC. All hematopoietic cells develop from hematopoietic stem cells through Flk2/Flt3-positive progenitor cells. Cell Stem Cell. 2011; 9:64-73.

12. Higuchi M, O'Brien D, Kumaravelu P, Lenny N, Yeoh EJ, Downing JR. Expression of a conditional AML1-ETO oncogene bypasses embryonic lethality and establishes a murine model of human $\mathrm{t}(8 ; 21)$ acute myeloid leukemia. Cancer Cell. 2002; 1:63-74.

13. Nishida S, Hosen N, Shirakata T, Kanato K, Yanagihara M, Nakatsuka S, Hoshida Y, Nakazawa T, Harada Y, Tatsumi N, Tsuboi A, Kawakami M, Oka Y, Oji Y, Aozasa K, Kawase I, et al. AML1-ETO rapidly induces acute myeloblastic leukemia in cooperation with the Wilms tumor gene, WT1. Blood. 2006; 107:3303-3312.

14. Yuan Y, Zhou L, Miyamoto T, Iwasaki H, Harakawa N, Hetherington CJ, Burel SA, Lagasse E, Weissman IL, Akashi K, Zhang DE. AML1-ETO expression is directly involved in the development of acute myeloid leukemia in the presence of additional mutations. Proc Natl Acad Sci U S A. 2001; 98:10398-10403.

15. Mulloy JC, Cammenga J, Berguido FJ, Wu K, Zhou P, Comenzo RL, Jhanwar S, Moore MA, Nimer SD. Maintaining the self-renewal and differentiation potential of human CD34+ hematopoietic cells using a single genetic element. Blood. 2003; 102:4369-4376. 
16. Vegi NM, Klappacher J, Oswald F, Mulaw MA, Mandoli A, Thiel VN, Bamezai S, Feder K, Martens JH, Rawat VP, Mandal T, Quintanilla-Martinez L, Spiekermann K, Hiddemann W, Dohner K, Dohner H, et al. MEIS2 Is an Oncogenic Partner in AML1-ETO-Positive AML. Cell Rep. 2016; 16:498-507.

17. Gilliland DG, Griffin JD. The roles of FLT3 in hematopoiesis and leukemia. Blood. 2002; 100:1532-1542.

18. Gilliland DG. Molecular genetics of human leukemias: new insights into therapy. Semin Hematol. 2002; 39:6-11.

19. Hatlen MA, Wang L, Nimer SD. AML1-ETO driven acute leukemia: insights into pathogenesis and potential therapeutic approaches. Front Med. 2012; 6:248-262.

20. Rawat VP, Cusan M, Deshpande A, Hiddemann W, Quintanilla-Martinez L, Humphries RK, Bohlander SK, Feuring-Buske M, Buske C. Ectopic expression of the homeobox gene $\mathrm{Cdx} 2$ is the transforming event in a mouse model of $\mathrm{t}(12 ; 13)(\mathrm{p} 13 ; \mathrm{q} 12)$ acute myeloid leukemia. Proc Natl Acad Sci U S A. 2004; 101:817-822.

21. Stadler CR, Vegi N, Mulaw MA, Edmaier KE, Rawat VP, Dolnik A, Bullinger L, Heilmeier B, Quintanilla-Fend L, Spiekermann K, Hiddemann W, Dohner K, Dohner $\mathrm{H}$, Feuring-Buske M, Buske C. The leukemogenicity of Hoxa9 depends on alternative splicing. Leukemia. 2014; 28:1838-1843.

22. Choi Y, Elagib KE, Delehanty LL, Goldfarb AN. Erythroid inhibition by the leukemic fusion AML1ETO is associated with impaired acetylation of the major erythroid transcription factor GATA-1. Cancer Res. 2006; 66:2990-2996.

23. Kojima K, Omoto E, Hara M, Sasaki K, Katayama Y, Nawa Y, Kimura Y, Azuma T, Takimoto H, Harada M. Myelodysplastic syndrome with translocation $(8 ; 21)$ : a distinct myelodysplastic syndrome entity or M2-acute myeloid leukemia with extensive myeloid maturation? Ann Hematol. 1998; 76:279-282.

24. Schwieger M, Lohler J, Friel J, Scheller M, Horak I, Stocking C. AML1-ETO inhibits maturation of multiple lymphohematopoietic lineages and induces myeloblast transformation in synergy with ICSBP deficiency. J Exp Med. 2002; 196:1227-1240.

25. Fenske TS, Pengue G, Mathews V, Hanson PT, Hamm SE, Riaz N, Graubert TA. Stem cell expression of the AML1/ ETO fusion protein induces a myeloproliferative disorder in mice. Proc Natl Acad Sci U S A. 2004; 101:15184-15189.

26. Gao H, Wu B, Le Y, Zhu Z. Homeobox protein VentX induces p53-independent apoptosis in cancer cells. Oncotarget. 2016; 7:39719-39729. doi: 10.18632/ oncotarget.9238.

27. Gao H, Le Y, Wu X, Silberstein LE, Giese RW, Zhu Z. VentX, a novel lymphoid-enhancing factor/T-cell factorassociated transcription repressor, is a putative tumor suppressor. Cancer Res. 2010; 70:202-211.

28. Harris NL, Jaffe ES, Diebold J, Flandrin G, MullerHermelink HK, Vardiman J, Lister TA, Bloomfield CD.
The World Health Organization classification of neoplastic diseases of the hematopoietic and lymphoid tissues. Report of the Clinical Advisory Committee meeting, Airlie House, Virginia, November, 1997. Ann Oncol. 1999; 10:1419-1432.

29. Bennett JM, Catovsky D, Daniel MT, Flandrin G, Galton DA, Gralnick HR, Sultan C. Proposals for the classification of the acute leukaemias. French-American-British (FAB) co-operative group. Br J Haematol. 1976; 33:451-458.

30. Imren S, Fabry ME, Westerman KA, Pawliuk R, Tang P, Rosten PM, Nagel RL, Leboulch P, Eaves CJ, Humphries RK. High-level beta-globin expression and preferred intragenic integration after lentiviral transduction of human cord blood stem cells. The Journal of clinical investigation. 2004; 114:953-962.

31. Deshpande AJ, Cusan M, Rawat VP, Reuter H, Krause A, Pott C, Quintanilla-Martinez L, Kakadia P, Kuchenbauer F, Ahmed F, Delabesse E, Hahn M, Lichter P, Kneba M, Hiddemann W, Macintyre E, et al. Acute myeloid leukemia is propagated by a leukemic stem cell with lymphoid characteristics in a mouse model of CALM/AF10-positive leukemia. Cancer Cell. 2006; 10:363-374.

32. Claus R, Wilop S, Hielscher T, Sonnet M, Dahl E, Galm O, Jost E, Plass C. A systematic comparison of quantitative high-resolution DNA methylation analysis and methylationspecific PCR. Epigenetics. 2012; 7:772-780.

33. Olk-Batz C, Poetsch AR, Nollke P, Claus R, Zucknick M, Sandrock I, Witte T, Strahm B, Hasle H, Zecca M, Stary J, Bergstraesser E, De Moerloose B, Trebo M, van den Heuvel-Eibrink MM, Wojcik D, et al. Aberrant DNA methylation characterizes juvenile myelomonocytic leukemia with poor outcome. Blood. 2011; 117:4871-4880.

34. Martin M. Cutadapt removes adapter sequences from high-throughput sequencing reads. EMBnetjournal, North America. 2011.

35. Trapnell C, Williams BA, Pertea G, Mortazavi A, Kwan G, van Baren MJ, Salzberg SL, Wold BJ, Pachter L. Transcript assembly and quantification by RNA-Seq reveals unannotated transcripts and isoform switching during cell differentiation. Nat Biotechnol. 2010; 28:511-515.

36. Team RC. R: A language and environment for statistical computing. R Foundation for Statistical Computing, Vienna, Austria. 2013.

37. Gentleman RC, Carey VJ, Bates DM, Bolstad B, Dettling M, Dudoit S, Ellis B, Gautier L, Ge Y, Gentry J, Hornik $\mathrm{K}$, Hothorn T, Huber W, Iacus S, Irizarry R, Leisch F, et al. Bioconductor: open software development for computational biology and bioinformatics. Genome Biol. 2004; 5:R80.

38. Subramanian A, Tamayo P, Mootha VK, Mukherjee S, Ebert BL, Gillette MA, Paulovich A, Pomeroy SL, Golub TR, Lander ES, Mesirov JP. Gene set enrichment analysis: a knowledge-based approach for interpreting genomewide expression profiles. Proc Natl Acad Sci U S A. 2005; 102:15545-15550. 